\title{
ESTUDOS PÓS-COLONIAIS E O EMPREGO DA CATEGORIA RACIAL NAS PESQUISAS EUROPEIAS: UMA ENTREVISTA COM MIGUEL MELLINO1
}

\author{
POST COLONIAL STUDIES AND THE USE OF RACIAL CATEGORY IN THE \\ EUROPEAN RESEARCHES: AN INTERVIEW WITH MIGUEL MELLINO
}

\section{ESTUDIOS POS-COLONIALES Y EL USO DE LA CATEGORÍA RACIAL EN LAS INVESTIGACIONES EUROPEAS: UNA ENTREVISTA CON EL PROFESOR MIGUEL MELLINOi}

\section{RESUMO}

A presente entrevista com o professor Miguel Angel Mellino, da Università degli studi di Napoli L'Orientale e membro do Centro Studi Postcoloniali e di Genere, tem o intuito de promover o debate acerca da construção dos estudos pós-coloniais no continente europeu, em particular no contexto italiano, e demonstrar o modo pelo qual é mobilizada a categoria racial na área das Ciências Sociais nesses espaços, destacando os limites impostos pelo passado colonialista e racista ainda não superado

PALAVRAS-CHAVE: Pós-colonialismo. Relações raciais. Europa. Itália.

\section{ABSTRACT}

This interview with Miguel Angel Mellino, professor at Università degli deli Studi di Napoli L'Orientale and member of the Centro Studi Postcoloniali e di Genere, has the aim to promote the debate about the construction of post-colonial studies in the European continent, in particular in the Italian context, and to show how the racial category is mobilized in the field of Social Sciences in these spaces, highlighting the limits imposed by a colonialist and racist past that has not been overcome yet.

KEYWORDS: Post-colonialism. Racial relations. Europe. Italy

\footnotetext{
${ }^{1}$ Tradução do italiano para o português realizada por Vinicio Corrias, doutorando em Língua e Literatura Italiana na Universidade de São Paulo, E-mail: niciocorrias@yahoo.it Revisão técnica realizada por Ana Lúcia Goulart de Faria, Pedagoga, doutora em Educação pela USP. Docente da Faculdade de Educação da Universidade Estadual de Campinas. Membro do Colegiado Docente de Doutorado da Università degli Studi di Milano-Bicocca. Coordenadora da linha Culturas Infantis do GEPEDISC (FE/Unicamp), membro da gestão 20162018 do FPEI, E-mail: cripeq@unicamp.br

${ }^{2}$ Mestre - Educação - Universidade Estadual de Campinas (UNICAMP - Campinas, SP. Brasil - Doutorando em Educação - Universidade Estadual de Campinas (UNICAM) - Campinas, SP. Brasil. E-mail: flavio.fravinho@gmail.com
}

Submetido em: 06/02/2018 - Aceito em: 08/03/2018 


\section{RESUMEN}

La presente entrevista con el profesor Miguel Ángel Mellino, de la Università degli studi di Napoli L'Orientale miembro del Centro Studi Postcoloniali e di Genere, tiene el objetivo de promover el debate sobre la construcción de estudios pos-coloniales en el continente europeo, en particular en el contexto de Italia, y mostrar la forma como es movilizada la categoría racial en el área de las ciencias sociales en eses espacios, destacando los límites impuestos por el pasado colonialista y racista aún no superado.

PALABRAS CLAVE: Pos-colonialismo, Relaciones raciales. Europa. Itália.

\section{APRESENTAÇÃO}

[...] expressões como "crítica pós-colonial" e/ou "teoria pós-colonial" [...] podemos definir uma particular filosofia da identidade, cujo primeiro objetivo é representado pela desconstrução daqueles princípios e noções que fundamentam a identidade moderna ocidental. (MELLINO, 2005, p. 115)

Miguel Angel Mellino é um dos mais destacados pesquisadores dos estudos póscoloniais e raciais da Itália, com uma longa carreira dedicada à "cátedra" de Antropologia cultural. Na Università degli studi di Napoli L'Orientale é docente das disciplinas "Estudos Póscoloniais" e "Relações Interétnicas" e membro do Collegio dei docenti del Dottorato in Studi Internazionali presso il Dipartimento di Scienze Umane e Sociali, do conselho do Corso di Laurea Magistrale in Relazioni e Istituzioni dell'Asia e dell'Africa e do conselho científico do Centro Studi Postcoloniali e di Genere. Tem diversos livros publicados, dentre eles Cittadinanze postcoloniali: appartenenze, razza e razzismo in Italia e in Europa (2012), Post orientalismo: Said e gli studi postcoloniali (2009) e La critica postcoloniale: descolonizzazione, capitalismo e cosmopolitismo nei postcolonial studies (2005); é autor, junto com Stuart Hall, do livro La cultura e il potere: conversazione sui Cultural Studies (2007), e com Anna Curcio de La razza al lavoro (2012). Também é organizador das publicações em italiano dos escritos políticos de Frantz Fanon, L'anno $V$ della rivoluzione algerina (2007) e Per la rivoluzione africana (2006).

No decorrer da entrevista, o professor apresenta o panorama do processo de construção dos estudos pós-coloniais no continente europeu, destacando as diferenças e similitudes entre os diversos países que possuem relevância na produção científica desse campo do saber, sobretudo na Itália. Também aponta de que forma a categoria raça está sendo mobilizada no âmbito das Ciências Sociais nos países europeus, expondo a gênese da resistência acadêmica para a sua utilização diante do passado fascista.

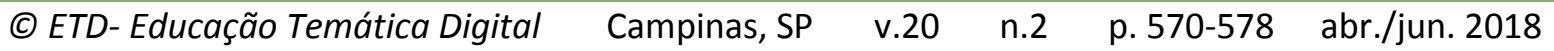




\section{ENTREVISTA ${ }^{3}$}

Flávio Santiago - Você é um dos principais teóricos pós-coloniais da Europa. Como percebe a construção desse campo teórico no berço epistêmico e político da colonização?

Miguel Mellino - Quando você fala em pós-colonialismo, você se refere aos estudos pós-coloniais ou ao pós-colonialismo como perspectiva?

Flávio Santiago - Aos estudos pós-coloniais.

Miguel Mellino - Eu faria uma distinção entre o que aconteceu com os estudos póscoloniais na Inglaterra, onde houve um desenvolvimento muito importante a partir dos anos 90 até mais ou menos 2005. Lá esses estudos foram uma corrente de estudos bastante hegemônica, não apenas na crítica literária; melhor dizendo, foi algo que nasceu na crítica literária e depois se expandiu para outros setores, até chegar inclusive às Ciências Políticas. Hoje, na Inglaterra, a mesma ideia, ou melhor, a mesma etiqueta de pós-colonial está meio em discussão, e diminuiu um pouco sua importância, não tanto pela perspectiva que abriram os estudos pós-coloniais. O que está sendo um tanto criticado é a forma pela qual os estudos pós-coloniais na Inglaterra se constituíram, tornando-se uma disciplina igual a todas as outras que fazem seu trabalho disciplinar, e foram incorporadas à academia, padronizando uma série de coisas que depois tornam-se um tipo de máquina do saber, um pouco impessoal e despolitizada. No entanto, repito, isso na Inglaterra é contra tornar disciplina os estudos póscoloniais.

A perspectiva pós-colonial avança; já existem muitas pessoas trabalhando nisso, ou que trabalharam. Talvez eles não usem muito o termo ou a direção, mas eles continuam a trabalhar dentro do terreno que abriram primeiramente os estudos culturais britânicos e depois os estudos pós-coloniais.

Na Europa, a situação é diferente. Eu penso que a Itália pode funcionar como exemplo do que aconteceu no resto da Europa continental; tem sido muito trabalhoso para os estudos pós-coloniais emergir, não apenas como estudos disciplinares, mas também como

\footnotetext{
${ }^{3}$ Realizada pessoalmente pelo autor deste texto, a partir de roteiro previamente elaborado e apresentado ao professor. Contudo, ao longo da conversação novas questões foram introduzidas e outras, modificadas. Para a publicação foi mantida a oralidade das falas.
}

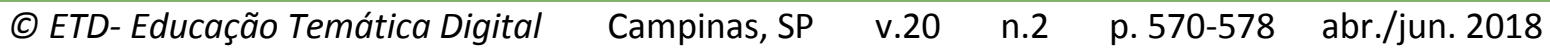


perspectiva. É apenas nos anos 2000 que você tem uma visão da perspectiva pós-colonial e dos estudos pós-coloniais. E mesmo hoje com muito esforço.

Na Itália, as "cátedras" de estudos pós-coloniais ou que, de algum modo, remetem ao pós-colonial de um ponto de vista formal, são pouquíssimas. Eu acho que a minha é uma dessas poucas; mas há outras, sobretudo em crítica literária. Existem outras pessoas que talvez se ocupem dos estudos culturais ou outras coisas relativas aos estudos pós-coloniais. Porém, falta, na universidade italiana, um reconhecimento para esses estudos em si. Isso não quer dizer que não existam pessoas que trabalhem com os estudos pós-coloniais ou com a perspectiva do pós-colonial, mas com certeza não podemos falar em hegemonia. E pareceme que isso aconteceu um pouco na Europa toda.

Eu viajo e o que vejo é que, em países como França, Alemanha, Suécia, os estudos póscoloniais estão emergindo, estão tendo muita visibilidade e ganharam para eles um espaço de reflexão mais visível do que na Itália. Em minha opinião, a grande diferença que pode ser traçada entre a diversidade de desenvolvimento na Inglaterra e na Europa continental devese sobretudo ao conceito de raça. Este último, no mundo anglo-saxão, encontra menos resistência, inclusive por parte da intelligentsia acadêmica progressista e de esquerda.

Ao contrário, na Europa continental, o tipo de perspectiva crítica que pode adotar o discurso pós-colonial tem muita dificuldade em assimilar a forma que, dentro de sua tradição, esse conceito emerge. Essa dificuldade deve-se ao fato de que o conceito de raça sempre encontrou resistência, justamente pelo fato de que a Europa continental sempre foi muito mais envolvida com o fascismo e o racismo. Depois que o fascismo acabou, a estratégia com o conceito de raça foi aquela de negar sua existência: a raça não existe ou a raça é um engano produzido por alguma outra coisa, o que é a abordagem que, tendencialmente, preferem os marxistas que sempre veem raça e racismo como um tipo de superestrutura.

Flávio Santiago - Como você vê as dinâmicas do racismo no contexto italiano? Você acha que são diferentes das experiências de racismo na América Latina?

Miguel Mellino - Olha, pelo que eu sei, sim. Na América Latina, por ser uma realidade mais permeada pelo conflito que o dispositivo colonial trouxe para a sociedade, existe uma reflexão sobre a questão racial, o racismo, que é muito diferente daquela que existe na Europa. Infelizmente, na Europa, excluindo a Inglaterra, o que prevalece é uma visão do racismo muito plasmada, ou como apêndice de um certo tipo de marxismo que eu, chamei

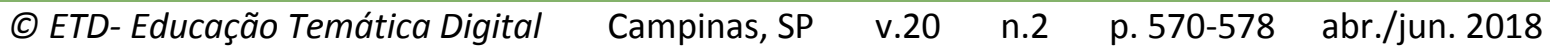


num texto meu, de marxismo branco ${ }^{4}$. Para mim, isso representa um limite e, na Europa Continental, é bem desgastante. Atualmente, em países como França, Inglaterra, Alemanha e, de fato, também um pouco na Itália, está emergindo algo diferente. Porém, ainda é muito trabalhoso, porque, na orientação mainstream e também por parte da teoria crítica ou da teoria antirracista, raça e racismo são vistos como algo que não tem sua especificidade, mas cujas causas devem ser procuradas na economia, na política ou em outras coisas. Fala-se mais de classe, fala-se mais de bom grado sobre outras coisas; mas de raça e racismo, como problema e como algo que está dentro da cultura da sociedade europeia, fala-se menos.

Então, sim, posso dizer que há uma diferença a respeito da forma com que o racismo é visto na América Latina e, também, veja, a Europa tem um problema específico com o passado colonial, no sentido de que, antes de os migrantes chegarem em massa aqui, ${ }^{5}$ na Europa não era claríssimo para os europeus o quanto sua identidade cultural, e mesmo a produção das sociedades europeias como população, eram construídas também a partir do dispositivo racial.

Flávio Santiago - Eu vejo que há muitos migrantes e vejo também por todo lado muitas expressões como "Não ao racismo" e "Não à deportação".

Miguel Mellino - "Não ao racismo" é mais difícil de ver; você vê mais, em favor dos migrantes, "Não à deportação", "Contra as fronteiras". Porém, racismo e antirracismo são usadas, mas, no meu ponto de vista, continuam sendo duas palavras sobre as quais não existe uma reflexão séria, nem mesmo dentro dos movimentos mais ligados à questão da emigração ou que trabalham diretamente com os migrantes. O problema existe pelo menos na Europa continental e eu estou falando sobretudo da Itália.

Flávio Santiago - Como você se percebe como homem branco pesquisando as relações étnico-raciais na Itália?

Miguel Mellino - Eu sou um pouco outsider em muitas coisas porque, apesar de ter participado da luta política dentro dos movimentos sociais, minha visão do racismo é muito diferente daquela que prevalece mesmo aqui neste ambiente. Portanto, com certeza, me vejo um pouco como outsider. Eu posso te dizer, muito modestamente, que boa parte do que são

\footnotetext{
${ }^{4}$ Para mais informações, ler: MELLINO, Miguel. Note sul metodo di Stuart Hall. Althusser, Gramsci e la questione della razza, Décalages, v. 2, n. 1, 2016. Disponível em: http://scholar.oxy.edu/decalages/vol2/iss1/12 . Acesso em: 20 dez. 2017. (Este artigo está sendo traduzido para o português e será publicado na Mouro: Revista Marxista)

${ }^{5}$ À Europa (NdT).
}

(C) ETD-Educação Temática Digital $\quad$ Campinas, SP $\quad$ v.20 $\quad$ n.2 $\quad$ p. 570-578 abr./jun. 2018 
hoje na Itália os estudos pós-coloniais passou pelas traduções e pelos trabalhos que eu fiz. Isso não quer dizer... não quero me atribuir nenhum caráter messiânico, mas penso ter sido um dos poucos que quiseram se dedicar especialmente a esse tema. Porque o que aconteceu com outras pessoas que trabalham com os estudos pós-coloniais é que eles adicionaram algumas coisas dos estudos pós-coloniais, ou dos estudos subalternos, ou feminismo póscolonial ao seu trabalho anterior, às coisas sobre as quais já estavam trabalhando.

Mesmo assim, tudo bem, mas, se você quiser achar um defeito na Itália pela falta de visibilidade da reflexão pós-colonial, talvez seja isso, isto é, os estudos pós-coloniais foram anexados a tantas coisas, mas não conseguiram criar uma reflexão global que conseguisse afetar a forma que a Itália produz e reproduz a própria identidade, a própria noção de história, os próprios dispositivos de saber na universidade e assim por diante. Não sei se ficou claro.

Flávio Santiago - Sim, ficou claro. Uma coisa que eu penso é: como a experiência de uma pessoa que faz pesquisa na Itália influencia essa construção?

Miguel Mellino - Você quer dizer de que forma a pesquisa influencia a concepção que essas pessoas têm do racismo?

Flávio Santiago - Sim.

Miguel Mellino - Sabe o que acontece? Muitos pesquisam, por exemplo, sobre os migrantes. E, ao fazer pesquisa de algo relacionado com os migrantes, você vai terminar falando de questões que têm a ver com raça e racismo. O problema é sempre o mesmo, ou seja, exceto alguns pesquisadores que conseguem superar um pouco esses limites, no final tudo é realizado dentro de um tipo de esquema teórico já consolidado a respeito dessas coisas.

Flávio Santiago - Quem são as pessoas que fazem essas pesquisas?

Miguel Mellino - Há muitos doutorandos e os sociólogos.

Flávio Santiago - Cidadãos italianos?

Miguel Mellino - Então, esse é outro dos grandes problemas da questão que expliquei antes. Se, na França, na Alemanha, na Suécia, os estudos pós-coloniais estão tendo um impacto de visibilidade maior que na Itália, isso é relacionado ao fato de que lá os intelectuais que têm um passado de migrantes, ou que nasceram nesses países, mas têm pele escura ou vêm de uma família que não é estritamente europeia, têm acesso aos lugares de produção de conhecimento na universidade. Na Itália, pelo contrário, isso não acontece. São

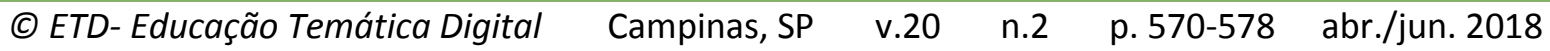


pouquíssimos os italianos "não italianos" que conseguem trabalhar nas universidades ou ter acesso aos lugares-chave da produção do conhecimento ou da arte na televisão, nas mídias, nos jornais. $E$ isso é um problema, não porque tem que ser necessariamente alguém não branco ou sul-americano quem levanta a questão, e sim o fato de na Itália não existir esse percurso, justamente porque a Itália é uma sociedade profundamente racista. Ela é racista em sua estrutura material e, portanto, não permite que os migrantes (após quarenta ou cinquenta anos de imigração) cheguem a esses lugares, e por isso os imigrantes veem a Itália apenas como um lugar de passagem para chegar a outros países

Isso, que aparece muito na reflexão local, sendo atribuído ao fato de a economia italiana não ser desenvolvida como a alemã ou outras. Porém, na realidade não é assim: recentemente eu fui para Portugal, que tem uma situação mais ou menos parecida com a italiana.

Em Portugal, entram muitos brasileiros. Eles vão estudar lá, depois fazem carreira na universidade e apoiam esse tipo de discurso; embora sejam poucos, embora Portugal seja aparentemente mais reacionário em relação ao racismo, teoricamente, do que a Itália. Mas pelo menos em Portugal você tem a possibilidade de pôr em discussão esse mecanismo. Na Itália, isso é muito mais difícil de acontecer. Tudo isso mostra que o racismo não é apenas uma questão discursiva ou de representação, mas que existe nas estruturas materiais da sociedade. E a estrutura material da sociedade italiana não permite absolutamente que os estrangeiros possam crescer e ter na Itália as mesmas possibilidades de mobilidade social, cultural e política dos italianos. Isso é um problema de segregação que na Itália não é enfrentado. Entendeu?

Flávio Santiago - Mas por quê?

Miguel Mellino - Porque, em minha opinião, a parte que poderia ter questionado isso, que é a parte mais crítica da sociedade, que sustenta um certo tipo de discurso antirracista. Sábado, por exemplo, há uma manifestação muito importante ${ }^{6}$, você vai ver muitas pessoas...

Flávio Santiago - Em Nápoles ou em Roma?

\footnotetext{
${ }^{6}$ Para mais detalhes, acesse: MIGRANTI, a Roma i movimenti in corteo per chiedere "Diritti senza confini. La Repubblica. 16 dez. 2017. Disponível em: http://roma.repubblica.it/cronaca/2017/12/16/news/ diritti senza confini a roma i movimenti in corte o-184317955/ Acesso em: 20 dez. 2017.
}

(C) ETD- Educação Temática Digital Campinas, SP $\quad$ v.20 $\quad$ n.2 $\quad$ p. 570-578 abr./jun. 2018 
Miguel Mellino - Em Roma...Você vai ver uma manifestação sobre esses temas com milhares de pessoas, algo talvez único na Europa, relativamente ao número de pessoas ou de movimentos e organizações políticas envolvidas. Em minha opinião, o problema é que eles leem o fenômeno de um ponto de vista limitado. Porque, se você vai ver o programa dessa manifestação e suas palavras de ordem, raça e racismo não estão presentes. Fala-se de luta às fronteiras, de luta para os direitos, do fato de hoje na Itália haver pobres como migrantes. Porém, não se chega a entender o limite estrutural que os migrantes sempre têm que enfrentar e que é um limite de racismo na sociedade italiana, de racismo como estrutura material.

Se amanhã desaparecessem, casualmente, as fronteiras nacionais, se houvesse uma anistia geral, se houvesse, por exemplo, falo por paradoxo, a possibilidade para os migrantes de virem para a Itália com um visto de estudo e trabalho, vai ter o mesmo problema, porque não é um problema de fronteira. É um problema político, cultural e econômico que tem a ver com a história da Europa e da Itália, e que tem a ver com a relação da Itália com o colonialismo e o racismo, que nunca foi superada.

O novo plano que o governo implementou para a integração é totalmente modelado em cima de algo que podemos definir mais "ius culturae" 7 do que "ius soli" 8 ; isso porque quem poderá obter a cidadania italiana ${ }^{9}$ tem que dominar a língua, tem que ter um certo tipo de conhecimento da língua e da cultura italianas, e coisas desse tipo. Aqui você vê o racismo reproposto de outro ponto de vista. O paradoxo é que uma parte da esquerda, aquela institucional ou progressista italiana, apoia esse tipo de visão, como a não matrícula das crianças na escola. Porque é sempre a mesma coisa: aqui o problema continua sendo o migrante e não a sociedade italiana. O problema tem que ser a sociedade italiana e não o migrante.

Flávio Santiago: Agradeço ao professor Miguel Angel Mellino por ter gentilmente me concedido esta entrevista na cidade de Nápoles, em dezembro de 2017, durante meu "estágio sanduíche", que está sendo desenvolvido junto à Università degli Studi di Milano-Bicocca, sob

\footnotetext{
${ }^{7}$ Ius culturae: expressão latina que significa "direito da cultura". Trata-se de um princípio jurídico recentemente discutido na Itália que liga a aquisição da cidadania, para uma pessoa que chegou ao país antes de completar 12 anos, ao fato de ter feito pelo menos cinco anos de escola nesse país (nt.).

${ }^{8}$ Ius soli: expressão latina que significa "direito da terra". A expressão é hoje usada para indicar a aquisição da cidadania com base no fato de a pessoa ter nascido nesse país (nt.).

9 Para maiores informações acessar: https://www.avvenire.it/attualita/pagine/cosi-oggi-uno-straniero-puodiventare-italiano Acesso em: 22 dez. 2017.
}

(C) ETD- Educação Temática Digital Campinas, SP $\quad$ v.20 $\quad$ n.2 $\quad$ p. 570-578 abr./jun. 2018 
supervisão da professora Agnese Infantino, no contexto do doutorado realizado na Faculdade de Educação da Universidade Estadual de Campinas (UNICAMP), sob a orientação da professora Ana Lúcia Goulart de Faria, com o financiamento da Fundação de Amparo à Pesquisa do Estado de São Paulo (FAPESP) - Bolsa Estágio de Pesquisa no Exterior - BEPE.

\section{REFERÊNCIAS}

CURCIO, Anna; MELLINO; Miguel A. La razza al lavoro. Roma: Manifestolibri, 2012.

FANON, Frantz. Scritti politici: per la rivoluzione africana. Roma: Derive Approdi, 2006.

FANON, Frantz. Scritti politici: I'anno V della rivoluzione algerina. Roma: Derive Approdi, 2007.

HALL, Stuart; MELLINO, Miguel A. La cultura e il potere: conversazione sui cultural studies. Milano: Meltemi, 2007.

MELLINO, Miguel A. (Org.). La critica postcoloniale: descolonizzazione, capitalismo e cosmopolitismo nei postcolonial studies. Roma: Meltemi, 2005.

MELLINO, Miguel A. Post-orientalismo: said e gli studi postcoloniali. Milano: Booklet Milano, 2009.

MELLINO, Miguel A. Cittadinanze postcoloniali: appartenenze, razza e razzismo in Italia e in Europa. Roma: Carocci, 2012.

' Revisão gramatical do texto sob a responsabilidade de Wilma Rigolon. Mestre em Língua Portuguesa, pela PUC/SP. e-mail: wilma.rigolon@gmail.com 